\title{
The effect of limited proteolysis by different proteases on the formation of whey protein fibrils
}

\author{
Yu-Zhe Gao, Hong-Hua Xu, ${ }^{1}$ Ting-Ting Ju, and Xin-Huai Zhao \\ Key Laboratory of Dairy Science, Ministry of Education, Northeast Agricultural University, 150030 Harbin, People's Republic of China
}

\begin{abstract}
Four proteases: trypsin, protease A, pepsin, and protease $\mathrm{M}$ were selected to modify whey protein concentrate (WPC) at a low degree of hydrolysis $(0.1,0.2$, and $0.3 \%$ ) before adjusting to $\mathrm{pH} 2.0$ and heating at $90^{\circ} \mathrm{C}$ to gain insight into the influence of proteolysis on fibril formation. The kinetics of fibril formation were performed on native and modified WPC using the fluorescent dye thioflavin $\mathrm{T}$ in conjunction with transmission electron microscopy and far-UV circular dichroism spectroscopy for the morphological and secondary structural analyses. The change in surface hydrophobicity and content of free sulfhydryl groups were also observed during the formation of fibrils for the native and modified WPC. The content of aggregation and thioflavin $\mathrm{T}$ kinetic data indicated that the ability of fibril formation was apparently different for WPC modified by the 4 proteases. Whey protein concentrate modified by trypsin aggregated more during heating and the fibril formation rate was faster than that of the native WPC. Whey protein concentrate modified by the other proteases showed slower aggregation with worse amyloid fibril morphology. Compared with the native WPC, the structure of WPC changed differently after being modified by proteases. The state of $\alpha$-helix structure for modified WPC played the most important role in the formation of fibrils. Under the mild conditions used in this work, the $\alpha$-helix structure of WPC modified by trypsin caused little destruction and resulted in fibrils with good morphology; the content of $\alpha$-helices for WPC modified by other proteases decreased to 36.19 to $50.94 \%$; thus, fibril formation was inhibited. In addition, it was beneficial for the modified WPC to form fibrils such that the surface hydrophobicity increased and the content of free sulfhydryl groups slightly decreased during heating.
\end{abstract}

Key words: whey protein concentrate, fibril, protease hydrolysis, structure change

Received March 22, 2013.

Accepted August 13, 2013.

${ }^{1}$ Corresponding author: xhh3161@126.com

\section{INTRODUCTION}

Amyloid fibrils aggregation has been found in many globular proteins, such as $\beta-\mathrm{LG}$, soy protein, immunoglobulins, and $\alpha$-LA at low $\mathrm{pH}$ and low ionic strength (Carrotta et al., 2001; Goers et al., 2002; Khurana et al., 2003). Amyloid fibrils share similar morphological features, as they are a few nanometers thick, branched or unbranched, often twisted, and characterized by a stacked-protein $\beta$-sheet structure (Dobson, 1999; Morozova-Roche et al., 2000; Rochet and Lansbury, 2000; Couzin, 2002; Khurana et al., 2003). The aqueous solution of a globular protein changes the balance of forces determining the position of the equilibrium between folded and unfolded states. The noncovalent interactions such as hydrophobicity, hydrogen bonding, van der Waals' forces, and the ionic bond play important roles in stabilizing fibrils, whereas the disulfide bonding between protein molecules does not occur to any significant extent because cysteine residues are predominantly protonated for self-assembly into amyloid fibrils (Otte et al., 2000; Alting et al., 2002).

Almost all published studies of heat-induced $\beta-\mathrm{LG}$ self-assembly into amyloid-like fibrils at low $\mathrm{pH}$ and low ionic strength have not shown whether hydrolysis is a necessary precursor to the nucleation or growth of fibrils. Some reviews consider that the fibrils consist of small peptides formed by hydrolysis of the globular protein during long-time heating at low $\mathrm{pH}$. The kinetics of hydrolysis and the formation of fibril for $\beta-L G$ also show that the protein first needs to be hydrolyzed and that subsequently the peptides associate into the fibrils. Adamcik and Mezzenga (2011) worked on the fibril formation of $\beta$-LG at $\mathrm{pH} 2.0$ and found that the association of peptides into mature semi-flexible fibrils is quite complex. It involves the formation of proto-fibrils of aligned peptides that associate sidewise into twisted ribbons that subsequently transform into helical structures or even closed nanotubes. However, some papers have reported that not all peptides actually incorporate into fibrils. Lara et al. (2012) found that hydrolysis precedes aggregation into either type of aggregate and suggested that different peptides form different structures, including long semi-flexible fibrils and shorter flexible strands. 
Although the above results suggest that hydrolysis is essential for fibril formation, the hydrolysis in these papers is acid hydrolysis, which occurs during longtime heating in an aqueous medium at low $\mathrm{pH}$. In the current research, whey protein concentrate (WPC) was first hydrolyzed by proteases at mild conditions and then the modified WPC was heated to form fibrils at $90^{\circ} \mathrm{C}$ and $\mathrm{pH} 2.0$ to confirm whether proteolysis is beneficial to fibril formation. To compare the ability of WPC modified by different proteases to form fibrils, 4 proteases that cleave to different peptide bonds were selected. We also analyzed the relationship between the changed secondary structure of modified WPC and the formation of fibrils.

\section{MATERIALS AND METHODS}

\section{Materials}

Whey protein concentrate was purchased from Hilmar Cheese Co. (Hilmar, CA). The composition of the WPC was 76.94 weight percent protein (measured from Kjeldahl analysis: $\mathrm{N} \times 6.38)$ with the major proteins. Trypsin (EC 3.4.21.4) and pepsin (EC 3.4.23.1) were purchased from Sigma-Aldrich (St. Louis, MO); protease A "Amano" 2G and protease M "Amano" G were purchased from Amano Enzyme Inc., Japan. Thioflavin $\mathrm{T}$ ( Th T) powder and 1-anilino-8-naphthalene sulfonate (ANS) powder were purchased from Sigma-Aldrich. All other reagents and chemicals were of analytical grade and purchased from the local market.

\section{Limited Proteolysis of Whey Protein Concentrate}

Whey protein concentrate was added to Milli-Q water (Millipore Corp., Billerica, MA) to make a 7.9\% (wt/ vol) dispersion. Hydrolysis was performed for $30 \mathrm{~min}$ at $30^{\circ} \mathrm{C}(\mathrm{pH} 6.7)$, except pepsin, for which it was performed at $\mathrm{pH}$ 2.0. The degree of hydrolysis (DH) with different amounts of proteases added was controlled and determined by using the $\mathrm{pH}$-state method (AdlerNissen, 1986), which determined the DH percentage on the basis of the number of free titratable amino groups produced by hydrolysis of peptide bonds. The DH was calculated using the following equation:

$$
\mathrm{DH}=\frac{V_{\mathrm{NaOH}} \times N_{\mathrm{NaOH}}}{\alpha \times M P \times h_{t o t}} \times 100 \%,
$$

where $V_{\mathrm{NaOH}}$ was the titrant volume of $\mathrm{NaOH}, N_{\mathrm{NaOH}}$ was the concentration of $\mathrm{NaOH}(0.1 \mathrm{~mol} / \mathrm{L})$, $\alpha$ was the degree of dissociation of $\alpha$-amino groups, $M P$ was the mass of protein $(\mathrm{g})$, and $h_{t o t}$ was the number of peptide bonds in the substrate $(\mathrm{mEq} / \mathrm{g}$ of protein). The $\alpha$ value was 0.44 and $h_{\text {tot }}$ was 7.8 (Adler-Nissen, 1986). When the $\mathrm{DH}$ reached 0.1 to $0.3 \%$, the WPC hydrolysate was set to $\mathrm{pH} 2.0$ and centrifuged at 19,000 $\times g$ for $30 \mathrm{~min}$ at $4^{\circ} \mathrm{C}$ as soon as possible, as hydrolysis proceeded very slowly at $4^{\circ} \mathrm{C}$.

\section{Modified WPC Aggregation}

Whey protein concentrate aggregation was determined by the method of Kurouski et al. (2012) with some modification. The native and hydrolyzed WPC solution was set to $\mathrm{pH} 2.0$ by adding a $6 \mathrm{M} \mathrm{HCl} \mathrm{so-}$ lution and centrifuged $19,000 \times \mathrm{g}$ for $30 \mathrm{~min}$ at $4^{\circ} \mathrm{C}$ to remove undissolved protein. The supernatant was diluted to 3 weight percent with Milli-Q water, the protein concentration was determined by Kjeldahl analysis $(\mathrm{N} \times 6.38)$, and then the solutions were adjusted to $\mathrm{pH} 2.0$ with $6 \mathrm{M} \mathrm{HCl}$. To induce fibril formation, the protein solution was heated for $10 \mathrm{~h}$ at $90^{\circ} \mathrm{C}$ in a water bath. Following the requisite heating time, the tube was cooled in ice water for 5 to $10 \mathrm{~min}$. Aliquots were $2 \mathrm{~mL}$ for the Th $\mathrm{T}$ assay, $20 \mathrm{~mL}$ for the content of aggregation, and $4 \mathrm{~mL}$ for the other assays.

\section{Fractionation of Protein Aggregation}

The 3 weight percent (protein basis) solutions of native and modified WPC by different proteases were added to tubes and heat treated at $90^{\circ} \mathrm{C}(\mathrm{pH} 2.0)$ in a water bath. The beginning of the holding time was, therefore, defined as the moment when the tubes were placed in the water bath. The concentration in the untreated sample was called $C_{0}$. After each hour passed, the samples were immediately cooled with cold water. The denatured and aggregated WPC were separated by a selective precipitation method (centrifuged at $15,000 \times g$ for $20 \mathrm{~min}$ at $4^{\circ} \mathrm{C}$; Veerman et al., 2002). The supernatant was defined by the non-aggregation concentration at time $t\left(C_{t}\right)$, which was determined by means of the Kjeldahl method $(\mathrm{N} \times 6.38)$.

The kinetic parameters (reaction rate constant $k$ and activation energy $E_{a}$ ) of disappearance of native whey protein were determined using nonlinear regression after integration of the general rate equation (Kessler and Beyer, 1991):

$$
-\mathrm{d}_{c} / \mathrm{d}_{t}=k_{n} \times C^{n},
$$

where $k_{n}$ was the apparent rate constant and $C^{n}$ was the exponential function.

After a heating time $t(\mathrm{~s})$, the initial concentration $C_{0}$ decreased to $C_{t}(\mathrm{~g} / \mathrm{L})$ and the ratio of $C_{t} / C_{0}$ could be obtained by integration: 


$$
\begin{gathered}
\mathrm{n} \neq 1 ;\left(\frac{C_{t}}{C_{0}}\right)^{1-n}=1+(n-1) k t \\
n=1 ; \ln \left(\frac{C_{t}}{C_{0}}\right)=-k t ; \\
E_{a}=-R T \ln (k)+c
\end{gathered}
$$

where $C_{t}$ was the native protein concentration at time $t, k=k_{n} C_{0}^{n-1}$ was the reaction rate constant $\left(s^{-1}\right)$, and $E_{a}$ was the reaction activation energy. The reaction order $n$ was adjusted to a value that made it possible to plot Equation 1 or 2 as a straight line. The rate constant $k$ was then calculated from the slopes of straight lines; $E_{a}$ was calculated from Equation 3 , where $R$ was the gas constant $(8.314 \mathrm{~J} / \mathrm{mol} \cdot \mathrm{K})$ and $T$ was the temperature in K, $c$ was the linear fit contrast with the curvature (Anthon and Barrett, 2002).

\section{Thioflavin T Fluorescence Assay}

A stock solution of $8.0 \mathrm{mg}$ of $\mathrm{Th} \mathrm{T}$ solute in $10 \mathrm{~mL}$ of phosphate $\mathrm{NaCl}$ buffer (10 $\mathrm{m} M$ phosphate and $150 \mathrm{mM}$ $\mathrm{NaCl}, \mathrm{pH} 7.0$ ) was filtered through a $0.2-\mathrm{mm}$ syringe filter (Millex-GS; Millipore Corp.). The stock solution was stored at $4^{\circ} \mathrm{C}$ in a brown glass bottle covered with aluminum foil. The working solution was prepared by diluting the stock solution 50 fold in phosphate- $\mathrm{NaCl}$ buffer (final Th $\mathrm{T}$ concentration of $60 \mathrm{mM}$ ). In the assay, $160 \mathrm{~mL}$ of sample was added to $4 \mathrm{~mL}$ of working solution; the mixture was vortexed briefly and held at room temperature for $1 \mathrm{~min}$ before measuring fluorescence (Hitachi F4500 fluorescence spectrometer; Hitachi High-Technologies Corp., Tokyo, Japan). Excitation and emission wavelengths were $460 \mathrm{~nm}$ and $490 \mathrm{~nm}$, respectively (Loveday et al., 2012).

\section{Nonlinear Regression of Thioflavin T Fluorescence}

According to the method of Loveday et al. (2012) with some modifications, thioflavin $\mathrm{T}$ fluorescence data were fitted with Equation 1, originally given by Morris et al. (2008). Note that we use this equation as an empirical curve-fitting function, in which $f_{t}$ was fluorescence at time $t$ and $\alpha, \beta$, and $\gamma$ were arbitrary constants:

$$
f_{t}=\alpha-\frac{\frac{\beta}{\gamma}+\alpha}{1+\frac{\beta}{\alpha \gamma} \exp [t(\beta+\alpha \gamma)]}
$$

The lag time $\left(t_{\text {lag }}\right)$, time for fluorescence to increase to half of its maximal value $\left(t_{1 / 2 \max }\right)$, and maximum rate of increase in fluorescence $\left[(\mathrm{d} f / \mathrm{d} t)_{\max }\right]$, were calculated with the analytical expressions in Equations 2 to 4, which were derived from Equation 1 in our earlier work (Loveday et al., 2010):

$$
\begin{gathered}
t_{1 / 2 \max }=\frac{\ln \left(2+\frac{\alpha \gamma}{\beta}\right)}{(\beta+\alpha \gamma)} ; \\
\left(\frac{\mathrm{d} f}{\mathrm{~d} t}\right)_{\max }=\frac{\left(\frac{\beta}{\gamma}+\alpha\right)(\beta+\alpha \gamma)}{4} ; \\
t_{\operatorname{lag}}=\frac{1}{\beta+\alpha \gamma}\left[\ln \left(\frac{\alpha \gamma}{\beta}\right)-4 \frac{\alpha \gamma}{\beta+\alpha \gamma}+2\right] .
\end{gathered}
$$

\section{Transmission Electron Microscopy}

The microstructure of heated protein dispersions was investigated by transmission electron microscopy $(\mathrm{H}-$ 7650; Hitachi High-Technologies Corp.) according to the procedure of Akkermans et al. (2008) with some modifications. A drop of the protein dispersion diluted to 0.02 weight percent in Millipore water was deposited onto an amorphous carbon film supported by a $\mathrm{Cu}$ grid. The excess product was removed after 15 min using filter paper. After drying the grid at room temperature for $10 \mathrm{~min}$, the samples were studied by transmission electron microscopy, operating at $80 \mathrm{kV}$.

\section{Surface Hydrophobicity Determination}

The surface hydrophobicity was measured by using ANS as fluorescent probes according to the method described by Hayakawa and Nakai (1985). Protein dispersions were diluted to $0.019,0.038,0.075$, and $0.15 \mathrm{mg} /$ $\mathrm{mL}$ with $0.01 M$ phosphate buffer ( $\mathrm{pH} 6.7$ ); then, aliquots $(20 \mu \mathrm{L})$ of ANS $(8.0 \mathrm{mmol} / \mathrm{L}$ in the same buffer) were added to $6 \mathrm{~mL}$ of the sample solutions, vortexed, and kept in the dark for 15 min. The fluorescence intensities of the sample solutions were measured with a Hitachi F4500 fluorescence spectrometer at wavelengths of $390 \mathrm{~nm}$ (excitation) and $470 \mathrm{~nm}$ (emission). The initial slope of the plot of fluorescence intensity versus protein concentration, which was calculated by linear regression (in all cases, $\mathrm{R}^{2}$ values of $>0.95$ ), was used as an index of the surface hydrophobicity of the protein sample evaluated. All measurements were performed in triplicate. 
oh

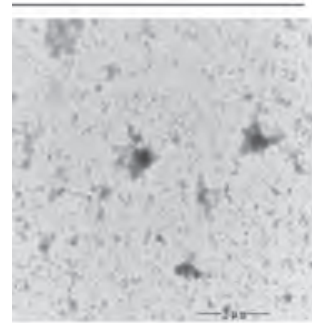

WPC

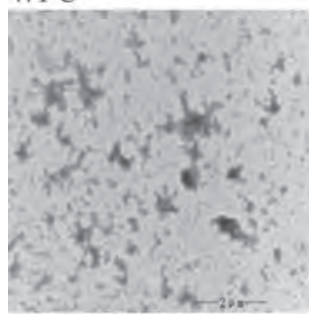

Modified WPC by trypsin

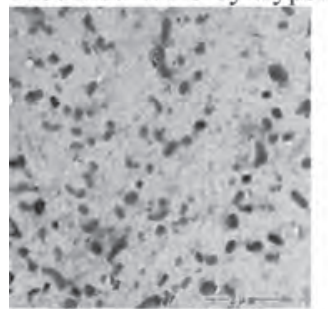

Modified WPC by protease A

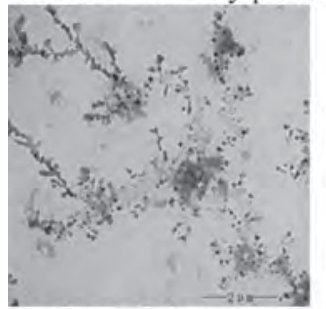

Modified WPC by pepsin

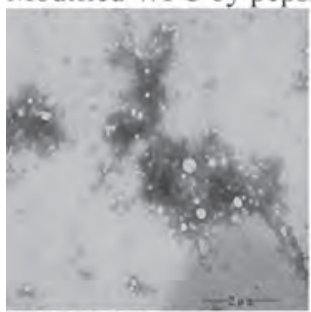

Modified WPC by protease M

$2 \mathrm{~h}$
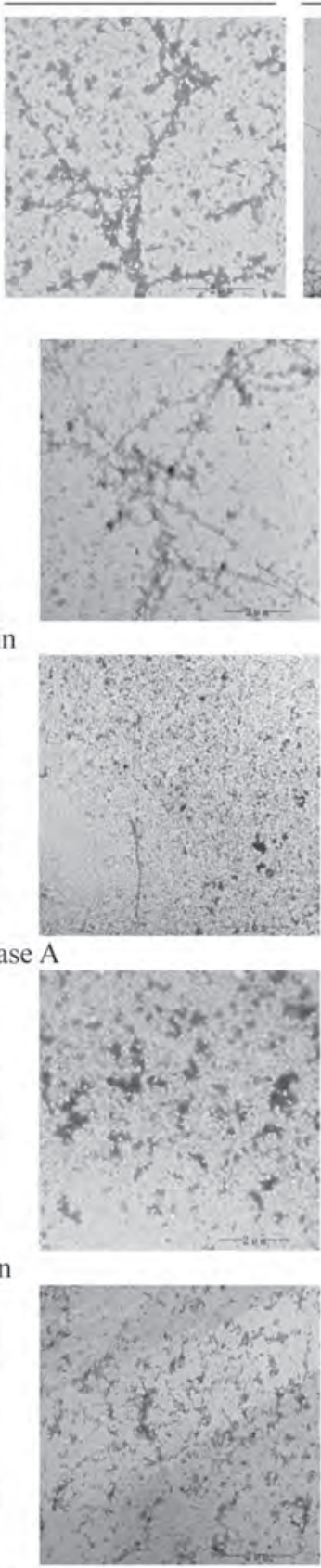

$5 \mathrm{~h}$
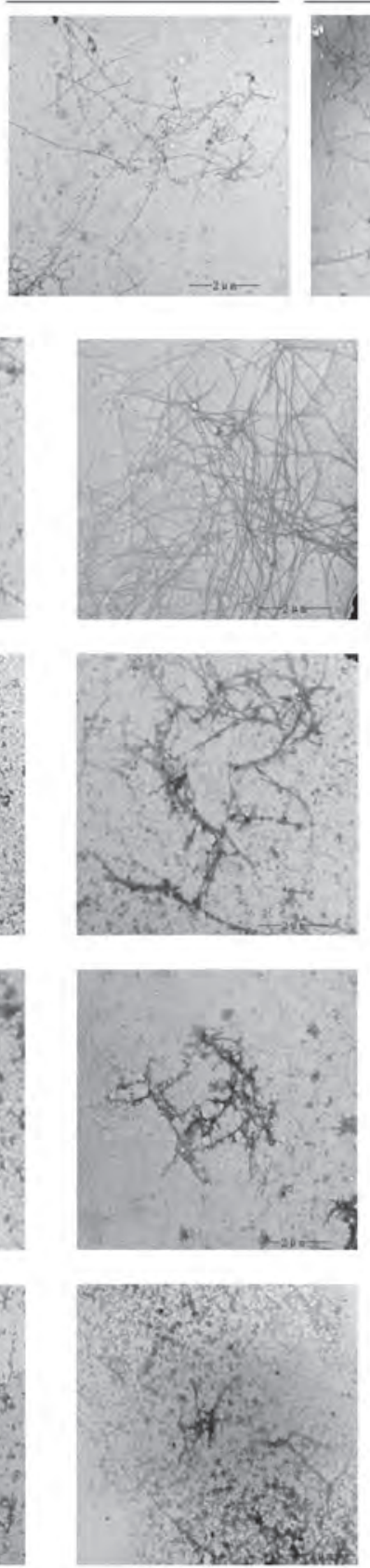

$10 \mathrm{~h}$
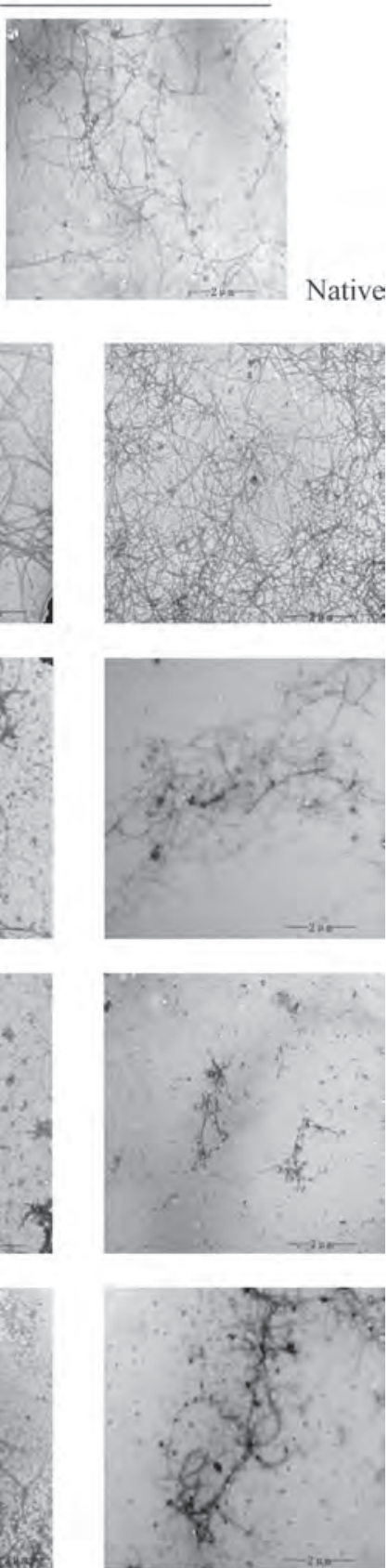

Figure 1. Transmission electron micrographs of the native whey protein concentrate (WPC) with 3 weight percent (protein basis) and 3 weight percent (protein basis) WPC modified by different proteases at different heating durations $(0,2,5$, and $10 \mathrm{~h})$ at $90^{\circ} \mathrm{C}(\mathrm{pH} 2.0)$.

\section{Determination of Free Sulfhydryl}

Free sulfhydryl (SH) contents in WPC solutions were determined using Ellman's reagent according to the method detailed by Beveridge et al. (1974), with some modifications. For SH content determination, $5 \mathrm{~mL}$ of the Tris-Gly buffer $(0.086 M$ Tris, $0.09 M$ glycine, and $0.004 M$ EDTA, pH 8.0) containing $8 M$ urea was added to $0.3 \mathrm{~mL}$ of $3 \%$ (wt/wt) WPC samples. Then, $20 \mu \mathrm{L}$ of 2,2'-dinitro-5,5'-dithiodibenzoate (DTNB; Merck KGaA, Darmstadt, Germany) was added; after 15 min, absorbance at $412 \mathrm{~nm}$ was measured with a spectropho- 
Table 1. Kinetic parameters for natural whey protein concentrate (WPC) and WPC modified by different proteases with a $0.2 \%$ degree of hydrolysis (DH), achieved by heating 3 weight percent (protein basis) WPC solutions $(\mathrm{pH} 2.0)$ at $90^{\circ} \mathrm{C}$

\begin{tabular}{lccccc}
\hline & & \multicolumn{3}{c}{ Modified WPC } \\
\cline { 3 - 5 } Kinetic parameter & Native WPC & Trypsin & Protease A & Pepsin & Protease M \\
\hline Rate constant $k_{n}\left[\left(\mathrm{gL}^{-1}\right)^{1-\mathrm{n}} \mathrm{s}^{-1}\right]^{1}$ & 0.0255 & 0.0412 & 0.0283 & 0.0267 & 0.0206 \\
$E_{a}(\mathrm{~kJ} / \mathrm{mol})^{2}$ & $9,146.13$ & $7,954.77$ & $8,888.37$ & $9,030.17$ & $9,682.18$ \\
\hline${ }^{1}$ The apparent reaction rate constant represents the kinetic disappearance of native whey protein; $\mathrm{n}=$ the \\
order of the reaction. \\
${ }^{2} E_{a}=$ reaction activation energy.
\end{tabular}

tometer (UV-2401 PC; Shimadzu Corp., Kyoto, Japan). The supernatants in buffer without DTNB were used as blanks. The calculation was as follows:

$$
\mathrm{SH}(\mu \mathrm{mol} / \mathrm{g})=\frac{\left(73.53 \times A_{412} \times D\right)}{C},
$$

where $A_{412}$ was the absorbance at $412 \mathrm{~nm}, C$ was the sample concentration $(\mathrm{mg} / \mathrm{mL}), D$ was the dilution factor, and 73.53 was derived from $10^{6} /\left(1.36 \times 10^{4}\right) ; 1.36$ $\times 10^{4}$ was the molar absorptivity and $10^{6}$ was for the conversion from molar basis to millimoles per milliliter basis and from milligrams of solids to grams of solids. All measurements were performed in triplicate.

\section{Circular Dichroism Spectroscopy}

Far-UV circular dichroism spectra were obtained using a J-815 spectropolarimeter (Jasco Corp., Tokyo, Japan) in 1-cm light path quartz cells according to the method of Kurouski et al. (2012) with some modification. All unheated and 10-h heated WPC modified by different protease solutions $(100 \mu \mathrm{L})$ were diluted with $2.9 \mathrm{~mL}$ of ice-cold $0.005 M$ Tris-HCl buffer (pH 7.5) and stored on ice until the circular dichroism measurements the next day and the samples were scanned from 190 to $280 \mathrm{~nm}$ with a scan rate of $100 \mathrm{~nm}$ per minute. Protein $\alpha$-helix percentage was evaluated using the formula of Yang et al. (1986):

$$
\alpha \text {-Helix }(\%)=\frac{-\left([\theta]_{222}+3,000\right)}{33,000},
$$

where $[\theta]_{222}$ was the ellipticity magnitude at a wavelength of $222 \mathrm{~nm}$. All measurements were performed in triplicate.

\section{Statistical Analysis}

An ANOVA was conducted using Microsoft Excel software (2003; Microsoft Corp., Redmond, WA). Rep- licate means were considered significantly different at $P<0.05$ unless stated differently. When significant differences were indicated by ANOVA, Tukey pairwise comparisons were performed to indicate where the differences between properties existed.

\section{RESULTS}

\section{Transmission Electron Microscopy Images of Modified WPC}

The native and modified WPC solutions [formed by hydrolysis of peptide bonds by proteases (trypsin, protease A, pepsin, and protease $\mathrm{M}$ )] were incubated to form the amyloid fibrils at $\mathrm{pH} 2.0$ and after heating for a long time, the morphology of amyloid fibrils aggregation was performed using transmission electron microscopy (Figure 1). Compared with the native WPC, WPC modified by trypsin formed more fibrils with longer and more semi-flexibility, especially as it could form massive unbranched fibrils after heating for $5 \mathrm{~h}$. Similarly the WPC modified by protease A, pepsin, and protease $M$ had difficulty in forming straight or gently curved amyloid fibrils, even after prolonged heating for $10 \mathrm{~h}$. The different results for fibril aggregate formation from modified WPC suggested that the protein structure probably was changed differently after modifying by different proteases; some of them were beneficial to the formation of fibrils, whereas some were not good for fibrils aggregation.

\section{Modified WPC Aggregation}

To quantify the degree of aggregation during the heating of native and modified WPC solutions by proteases, the ratios of non-aggregated to the initial protein concentrations were determined at varying heating times (Figure 2). Harper and Lansbury (1997) studied the aggregation models of amyloid protein in Alzheimer's disease and pointed out that the kinetics of aggregation consisted characteristically of 2 phases: an initial slow lag phase represented by the formation of 
aggregation nuclei and a subsequent and rapid growth phase in which the nucleus structure was extended into larger aggregates or fibrils. In our study, in the first hour, quite a few WPC aggregated in the lag phase. During heating for 2 to $5 \mathrm{~h}$, the native WPC and WPC modified by proteases aggregated rapidly at different rates; WPC modified by trypsin aggregated much faster and also demonstrated a larger rate constant $(k)$ and a lower activation energy $\left(E_{a}\right)$ of the aggregation reaction, which was less thermostable than native WPC and WPC solutions modified by other proteases, and thus aggregated more easily (Table 1 ).

\section{Thioflavin T Fluorescence}

Kinetic parameters of the fibril aggregation reactions, including lag time, maximum fluorescence intensity, and maximum aggregation rate (among other parameters), of modified WPC by different proteases were obtained by interpolating with the regression line. Model parameters and derived kinetic measures are shown in Table 2. The lag times to form fibrils were very important, which suggested that nucleation of fibrils occurred in the lag phase (Harper and Lansbury, 1997). The lag time of WPC modified by protease A was too short at 0.2 and $0.3 \% \mathrm{DH}$ to form nucleation of fibrils, whereas the lag times of WPC modified by pepsin and protease $\mathrm{M}$ were much longer than that of the native WPC; the lag time of WPC modified by trypsin was similar to that of the native WPC; too long or too short of a lag time affected the nucleation of fibrils. It is also shown

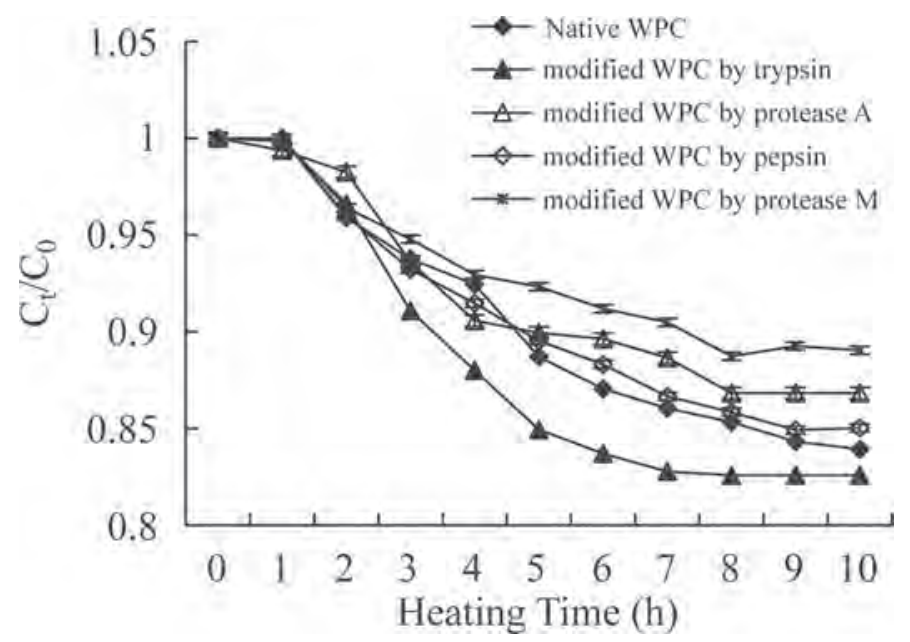

Figure 2. Fractional concentration of nonaggregated whey protein concentrate (WPC) by heating 3 weight percent (protein basis) native WPC solution and WPC modified by different proteases at $90^{\circ} \mathrm{C}(\mathrm{pH}$ 2.0) for different heating durations. Data are expressed as the mean \pm $\mathrm{SD}$ of 3 replicates. $C_{t}=$ native protein concentration at time $t ; C_{0}=$ initial concentration.

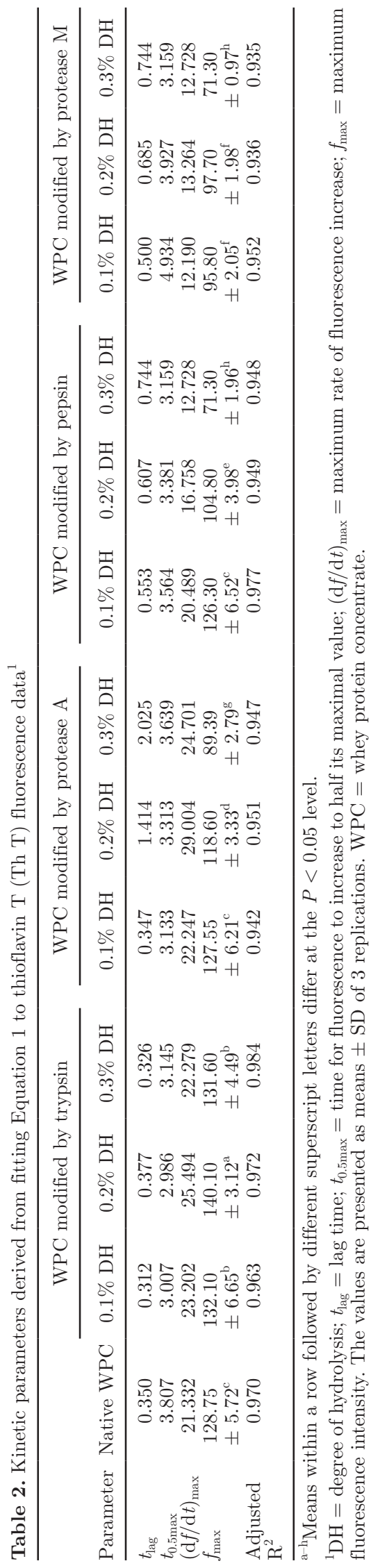


Table 3. Ellipticity magnitude $([\theta])$ at wavelength $(\lambda)=222 \mathrm{~nm}$ from circular dichroism spectroscopy and the $\alpha$-helix content calculated by the formula of Yang et al. (1986) in native whey protein concentrate (WPC) and WPC modified by proteases without heating and heating at $90^{\circ} \mathrm{C}$ for $10 \mathrm{~h}$

\begin{tabular}{|c|c|c|c|c|c|c|}
\hline \multirow[b]{2}{*}{ Parameter } & \multirow{2}{*}{$\begin{array}{l}\text { Heating } \\
\text { hours }(\mathrm{h})\end{array}$} & \multirow{2}{*}{$\begin{array}{l}\text { Native } \\
\text { WPC }\end{array}$} & \multicolumn{4}{|c|}{ Modified WPC } \\
\hline & & & Trypsin & Protease A & Pepsin & Protease M \\
\hline$[\theta]_{\lambda=222}$ & $\begin{array}{r}0 \\
10\end{array}$ & $\begin{array}{l}-22,037^{\mathrm{a}} \\
-14,680^{\mathrm{a}}\end{array}$ & $\begin{array}{l}-21,779^{\mathrm{a}} \\
-13,809^{\mathrm{b}}\end{array}$ & $\begin{array}{l}-15,144^{\mathrm{b}} \\
-11,041^{\mathrm{d}}\end{array}$ & $\begin{array}{l}-14,976^{\mathrm{b}} \\
-12,679^{\mathrm{c}}\end{array}$ & $\begin{array}{l}-12,486^{\mathrm{c}} \\
-11,726^{\mathrm{d}}\end{array}$ \\
\hline$\alpha$-Helix (\%) & $\begin{array}{r}0 \\
10\end{array}$ & $\begin{array}{l}57.68^{\mathrm{a}} \\
35.39^{\mathrm{a}}\end{array}$ & $\begin{array}{l}56.91^{\mathrm{a}} \\
32.75^{\mathrm{a}}\end{array}$ & $\begin{array}{l}36.80^{\mathrm{b}} \\
24.37^{\mathrm{c}}\end{array}$ & $\begin{array}{l}36.29^{\mathrm{b}} \\
29.33^{\mathrm{b}}\end{array}$ & $\begin{array}{l}28.29^{\circ} \\
26.44^{\circ}\end{array}$ \\
\hline
\end{tabular}

${ }^{\mathrm{a}-\mathrm{d}}$ Means within a row followed by different superscript letters differ at the $P<0.05$ level.

in Table 2 that $t_{0.5 \max }$ and $(\mathrm{d} f / \mathrm{d} t)_{\max }$ were different from those of the WPC modified by different proteases, especially the maximum $\mathrm{Th} \mathrm{T}$ fluorescence $\left(f_{\max }\right)$. The $f_{\max }$ of WPC modified by trypsin was higher than that of the native WPC, whereas the $f_{\max }$ of WPC modified by other proteases were much lower than that of the native WPC. Thioflavin $\mathrm{T}$ fluorescence could reflect the content of the $\beta$-sheet and even the rearrangement of the secondary structure, which was necessary for the fibrils aggregation (Loveday et al., 2012).

\section{DISCUSSION}

The secondary structural change of protein is very important for forming fibrils, with the $\alpha$-helical structure transitioning to $\beta$ strands and then associating into a regular fibrillar structure (Žerovnik, 2002). The $\alpha$-helix content (\%) was calculated by the formula of Yang et al. (1986) and it is shown in Table 3. On one hand, the $\alpha$-helix percentage decreased during heating due to some $\alpha$-helix possibly inversing to a $\beta$-type secondary structure (Tang et al., 2012); on the other hand, the $\alpha$-helix percentage of modified WPC decreased to a different extent after hydrolyzation by different proteases. Compared with the unheated native WPC, the $\alpha$-helix percentage of WPC modified by trypsin was similar to that of the native WPC, whereas it decreased 31.28 or $32.04 \%$, respectively, by modification with protease A or pepsin; the largest extent of decrease (43.34\%) was by modification with protease M. Thus, we hypothesized that if proteolysis led to the destruction of the $\alpha$-helix structure in WPC (especially when the $\alpha$-helix percentage decreased by $30 \%$ above), then it was very difficult to form good-morphology fibrils during the following heating aggregation.

The modification of WPC by proteases could bring about not only the change in secondary structure but also the content of free SH groups and the surface hydrophobicity change. The effect of proteolysis on the $\mathrm{SH}$ of WPC after heating for $10 \mathrm{~h}$ at $\mathrm{pH} 2.0$ is outlined in Figure 3. The content of SH in WPC modified by trypsin was similar to that of native WPC; in contrast, the SH content decreased greatly when WPC was modified by the other 3 proteases, especially at $0.3 \%$ $\mathrm{DH}$. The disulfide bonds played an insignificant role in forming fibrils; too many disulfide bonds were not good for forming fibrils, which probably accounted for noncovalent interactions contributing more to fibril aggregation reactions at low $\mathrm{pH}$ due to decreased electrostatic repulsion between WPC molecules (Hoffmann and van Mil, 1997). Thus, apart from trypsin, WPC modified by the other 3 proteases were prone to form disulfide bonds, which might be one of reasons for hardly forming good-morphology fibrils.

As shown in Tables 4 and 5, the ANS binding was highly influenced by the modification with proteases and the heating duration at $90^{\circ} \mathrm{C}$, which gave indications about the thermally induced conformational tran-
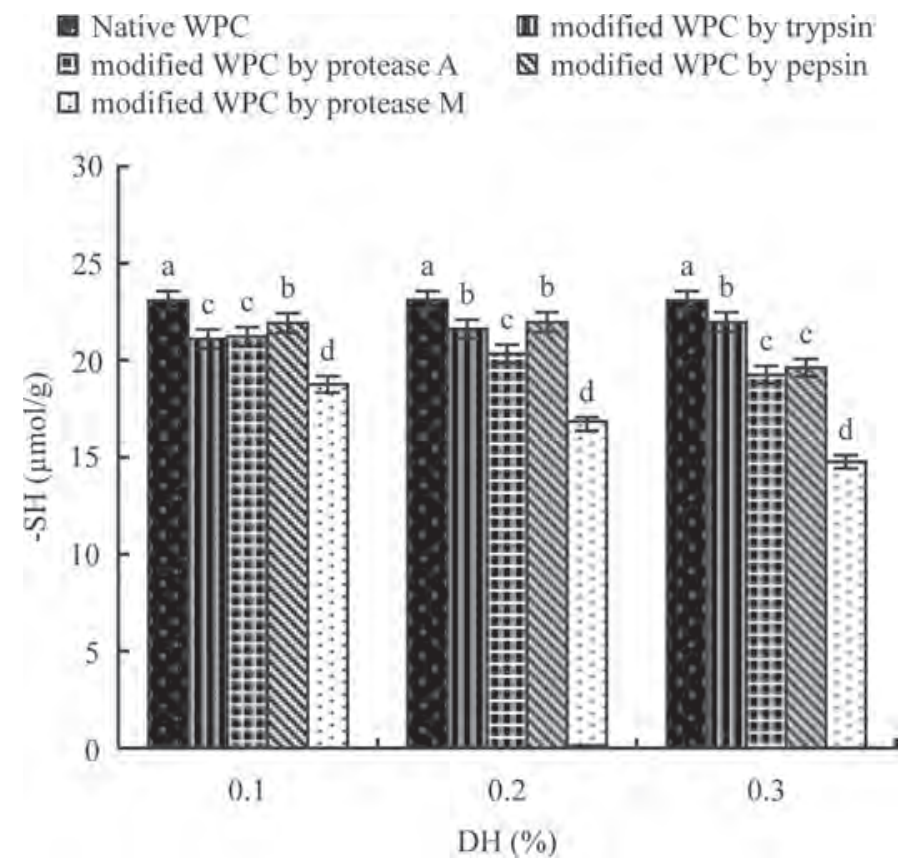

Figure 3. The content of free sulfhydryl groups (-SH) in native whey protein concentrate (WPC) and WPC modified by proteases at different degrees of hydrolysis (DH) from heating for $10 \mathrm{~h}$. The values are presented as means \pm SD of 3 replications. 


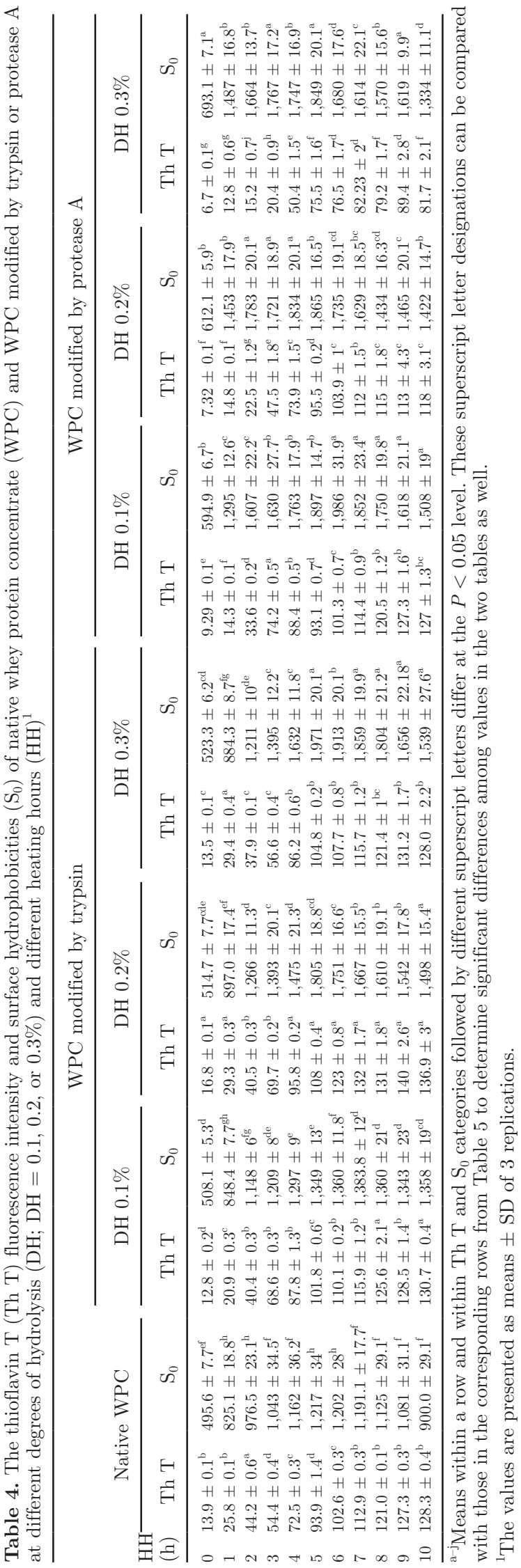

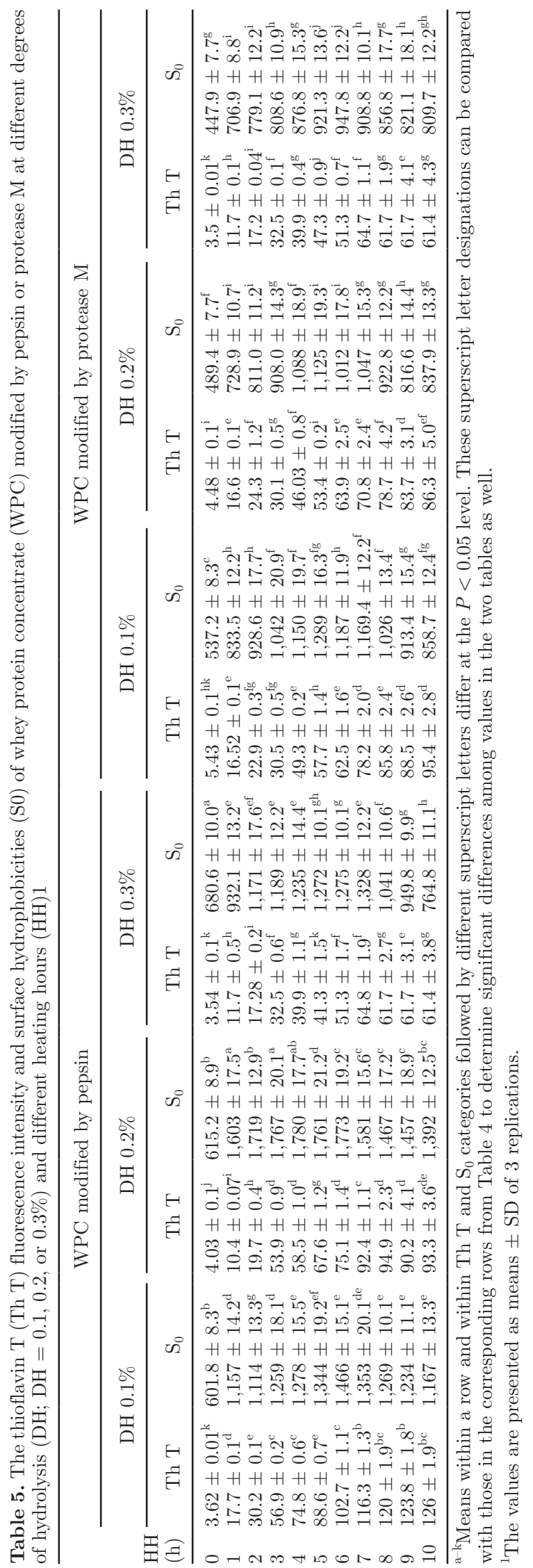


sition from the folded to unfolded state. During fibril formation, the surface hydrophobicity of native and modified WPC obviously increased, especially when heated for 5 to $6 \mathrm{~h}$, where it showed the maximum value. Furthermore, the surface hydrophobicity was quite different in WPC modified by different proteases; WPC modified by trypsin showed higher surface hydrophobicity, indicating that trypsin cleaved the peptide bond on the hydrophobic amino acids, such as arginine and lysine (Kishimura et al., 2007), which exposed more hydrophobic groups. The surface hydrophobicity of WPC modified by protease A $(0.2 \%$ and $0.3 \% \mathrm{DH})$ and pepsin increased less than that of WPC modified by trypsin, and WPC modified by protease M showed even lower surface hydrophobicity.

These results suggest that the structure of WPC changed differently after being modified by different proteases. The state of the $\alpha$-helix structure of modified WPC played the most important role in the formation of fibrils; once the $\alpha$-helix structure was destroyed, it was hard for modified WPC to form fibrils. In addition, the increased surface hydrophobicity and slightly decreased content of SH groups on the condition of minimum destruction of the $\alpha$-helix in WPC were of benefit in forming fibrils. Figure 4 shows typical stacked farUV circular dichroism spectra of the different WPC.

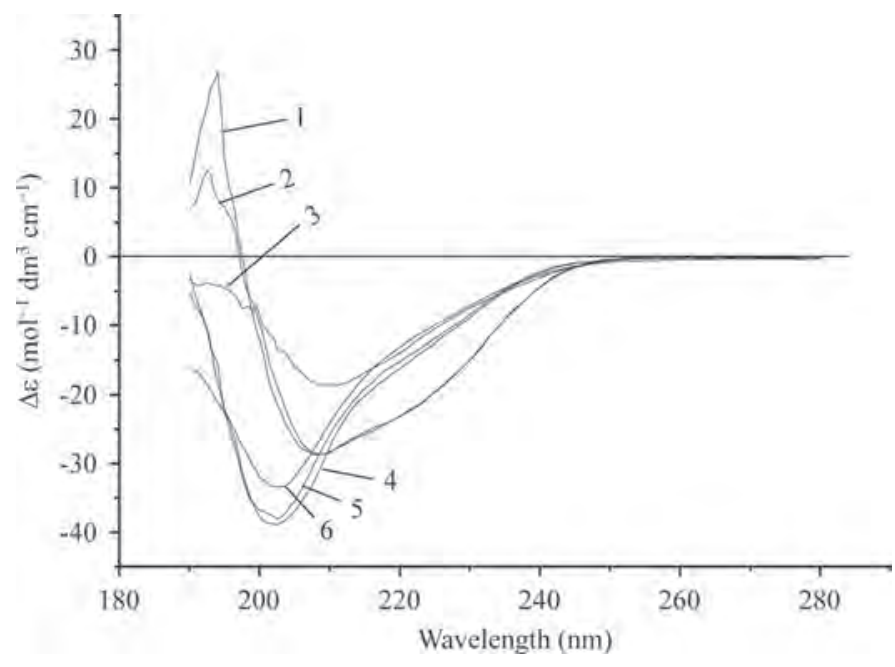

Figure 4. Typical stacked far-UV circular dichroism spectra of native whey protein concentrate (WPC) and WPC modified by proteases without heating and heating for $10 \mathrm{~h} .1=$ native unheated WPC; 2 $=$ unheated WPC modified by trypsin; $3=$ unheated WPC modified by protease M; $4=$ native WPC heated for $10 \mathrm{~h} ; 5=\mathrm{WPC}$ modified by trypsin and heated for $10 \mathrm{~h} ; 6=\mathrm{WPC}$ modified by protease $\mathrm{M}$ and heated for $10 \mathrm{~h} . \Delta \varepsilon$ is the $\mathrm{D}$-value of the absorption coefficient to polarized light.

\section{CONCLUSIONS}

Modification of WPC by various proteases before heating at $90^{\circ} \mathrm{C}(\mathrm{pH} 2.0)$ strongly affected the formation of amyloid fibrils. Compared with the native WPC, modification could shorten the time of fibril formation and increase the fibrils aggregation for WPC modified by trypsin, whereas WPC modified by other proteases aggregated more slowly, with longer lag times, even to the extent that it could not form amyloid fibrils. The reason for these differences might be related to the change in surface hydrophobicity, $\alpha$-helix structure, and the content of free SH groups. The surface hydrophobicity of WPC modified by proteases clearly increased, except that of WPC modified by protease M at $0.3 \% \mathrm{DH}$. The $\alpha$-helix structure of WPC modified by trypsin was only slightly disrupted and the content of SH was similar to that of the native WPC, with a slight decrease, which resulted in fibril formation with good morphology. The content of $\alpha$-helix for WPC modified by the other proteases decreased to 36.19 to $50.94 \%$ and the $\mathrm{SH}$ content decreased greatly, especially at $0.3 \% \mathrm{DH}$; thus, these WPC had difficulty in forming fibrils. As shown in our results, the major conditions for improving fibril formation for proteolysis might be the undestroyed $\alpha$-helix structure, increased surface hydrophobicity, and slightly decreased content of free SH groups.

\section{ACKNOWLEDGMENTS}

This work was supported by the National Natural Science Foundation of China (Beijing, China; No. 31071572), the Innovative Research Team of Higher Education of Heilongjiang Province (China; No. 2010td11), and the Program for Innovative Research Team of Northeast Agricultural University (Harbin, China; No. CXT007-1-3).

\section{REFERENCES}

Adamcik, J., and R. Mezzenga. 2011. Proteins fibrils from a polymer physics perspective. Macromolecules 45:1137-1150.

Adler-Nissen, J. 1986. A review of food protein hydrolysis specific areas. Pages 57-131 in Enzymic Hydrolysis of Food Proteins. Elsevier Applied Science Publications, New York, NY.

Alting, A. C., H. H. J. de Jongh, R. W. Visschers, and J.-W. F. A. Simons. 2002. Physical and chemical interactions in cold gelation of food proteins. J. Agric. Food Chem. 50:4682-4689.

Anthon, G. E., and D. M. Barrett. 2002. Kinetics parameters for the thermal inactivation of quality-related enzymes in carrots and potatoes. J. Agric. Food Chem. 50:4119-4125.

Beveridge, T., S. Toma, and S. Nakai. 1974. Determination of SH- and SS-groups in some food proteins using Ellman's reagent. J. Food Sci. 39:49-51.

Carrotta, R., R. Bauer, R. Waninge, and C. Rischel. 2001. Conformational characterization of oligomeric intermediates and aggregates in $\beta$-lactoglobulin heat aggregation. Protein Sci. 10:1312-1318. 
Couzin, J. 2002. Harmless proteins twist into troublemakers. Science 296:28-29.

Akkermans, C., P. Venema, A. J. van der Goot, H. Gruppen, E. J. Bakx, R. M. Boom, and E. van der Linden. 2008. Peptides are building blocks of heat-induced fibrillar protein aggregates of B-lactoglobulin formed at $\mathrm{pH} 2$. Biomacromolecules 9:1474-1479.

Dobson, C. M. 1999. Protein misfolding, evolution and disease. Trends Biochem. Sci. 24:329-332.

Goers, J., S. E. Permyakov, E. A. Permyakov, V. N. Uversky, and A. L. Fink. 2002. Conformational prerequisites for a-lactalbumin fibrillation. Biochemistry 41:12546-12551.

Harper, J. D., and P. T. Lansbury Jr. 1997. Models of amyloid seeding in Alzheimer's disease and scrapie: Mechanistic truths and physiological consequences of the time-dependent solubility of amyloid proteins. Annu. Rev. Biochem. 66:385-407.

Hayakawa, S., and S. Nakai. 1985. Relationships of hydrophobicity and net charge to the solubility of milk and soy proteins. J. Food Sci. 50:486-491.

Hoffmann, M. A. M., and P. J. J. M. van Mil. 1997. Heat-induced aggregation of $\beta$-lactoglobulin: Role of the free thiol group and disulfide bonds. J. Agric. Food Chem. 45:2942-2948.

Kessler, H.-G., and H.-J. Beyer. 1991. Thermal denaturation of whey proteins and its effect in dairy technology. Int. J. Biol. Macromol. $13: 165-173$.

Khurana, R., C. Ionescu-Zanetti, M. Pope, J. Li, L. Nielson, M. Ramírez-Alvarado, L. Regan, A. L. Fink, and S. A. Carter. 2003. A general model for amyloid fibril assembly based on morphological studies using atomic force microscopy. Biophys. J. 85:1135-1144.

Kishimura, H., Y. Tokuda, M. Yabe, S. Klomklao, S. Benjakul, and S. Ando. 2007. Trypsins from the pyloric ceca of jacopever (Sebastes schlegelii) and elkhorn sculpin (Alcichthys alcicornis): Isolation and characterization. Food Chem. 100:1490-1495.

Kurouski, D., H. Luo, V. Sereda, F. T. Robb, and I. K. Lednev. 2012. Rapid degradation kinetics of amyloid fibrils under mild conditions by an archaeal chaperonin. Biochem. Biophys. Res. Commun. 422:97-102.

Lara, C., S. Gourdin-Bertin, J. Adamcik, S. Bolisetty, and R. Mezzenga. 2012. Self-assembly of ovalbumin into amyloid and nonamyloid fibrils. Biomacromolecules 13:4213-4221.
Loveday, S. M., J. P. Hindmarsh, L. K. Creamer, and H. Singh. 2010. Physicochemical changes in intermediate-moisture protein bars made with whey protein or calcium caseinate. Food Res. Int. 43:1321-1328.

Loveday, S. M., X. L. Wang, M. A. Rao, S. G. Anema, and H. Singh. 2012. $\beta$-Lactoglobulin nanofibrils: Effect of temperature on fibril formation kinetics, fibril morphology and the rheological properties of fibril dispersions. Food Hydrocoll. 27:242-249.

Morozova-Roche, L. A., J. Zurdo, A. Spencer, W. Noppe, V. Receveur, D. B. Archer, M. Joniau, and C. M. Dobson. 2000. Amyloid fibril formation and seeding by wild-type human lysozyme and its disease-related mutational variants. J. Struct. Biol. 130:339-351.

Morris, A. M., M. A. Watzky, J. N. Agar, and R. G. Finke. 2008 Fitting neurological protein aggregation kinetic data via a 2-step, minimal/"Ockham's razor" model: The Finke-Watzky mechanism of nucleation followed by autocatalytic surface growth. Biochemistry $47: 2413-2427$.

Otte, J., M. Zakora, and K. B. Qvist. 2000. Involvement of disulfide bands in bovine $\beta$-lactoglobulin B gels set thermally at various $\mathrm{pH}$. J. Food Sci. 65:384-389.

Rochet, J.-C., and P. T. Lansbury Jr. 2000. Amyloid fibrillogenesis: Themes and variations. Curr. Opin. Struct. Biol. 10:60-68.

Tang, C.-H., S. S. Wang, and Q. Huang. 2012. Improvement of heatinduced fibril assembly of soy $\beta$-conglycinin (7S globulins) at $\mathrm{pH}$ 2.0 through electrostatic screening. Food Res. Int. 46:229-236.

Veerman, C., H. Ruis, L. M. C. Sagis, and E. van der Linden. 2002 Effect of electrostatic interactions on the percolation concentration of fibrillar $\beta$-lactoglobulin gels. Biomacromolecules 3:869-873.

Yang, J. T., C. S. C. Wu, and H. M. Martinez. 1986. Calculation of protein conformation from circular dichroism. Methods Enzymol. 130:208-269.

Žerovnik, E. 2002. Amyloid-fibril formation: Proposed mechanisms and relevance to conformational disease. Eur. J. Biochem. 269:3362-3371. 